\title{
Flow Assurance in Subsea Pipeline Design for Transportation of Petroleum Products
}

\author{
Son Tung Pham, Minh Huy Truong, Ba Tuan Pham \\ Faculty of Geology \& Petroleum Engineering, Hochiminh City University of Technology-Vietnam National University, Hochiminh, \\ Vietnam \\ Email:phamsontung@hcmut.edu.vn
}

How to cite this paper: Pham, S.T., Truong, M.H. and Pham, B.T. (2017) Flow Assurance in Subsea Pipeline Design for Transportation of Petroleum Products. Open Journal of Civil Engineering, 7, 311-323. https://doi.org/10.4236/ojce.2017.72021

Received: May 16, 2017

Accepted: June 23, 2017

Published: June 26, 2017

Copyright (c) 2017 by authors and Scientific Research Publishing Inc. This work is licensed under the Creative Commons Attribution International License (CC BY 4.0).

http://creativecommons.org/licenses/by/4.0/

(c) (i) Open Access

\begin{abstract}
Transportation of petroleum products through pipeline presents considerable risks including wax formation and deposition as a result of heat loss of fluids, which is harmful to the flow due to the reduced inner diameter or totally blocked pipelines in extreme cases. The production interruption due to blocked pipelines can cause colossal financial loss. Therefore, in order to diminish those adverse effects, it is critical that pipeline design for flow assurance should be considered. Flow assurance is a relatively new field in oil and gas industry, it means that the flow of hydrocarbon stream from one point to another must be ensured successfully and economically. Although flow assurance is extremely diverse, encompassing many discrete and specialized subjects and bridging across the full gamut of engineering disciplines, our work concentrated principally on the study of wax deposit in the pipelines. The main purpose of this paper is to focus on the aspect of material in pipeline design and the selection of thermal insulation coatings. Furthermore, operating parameters such as pressure, temperature and flowrate will be examined to achieve optimum results. For the case study in this paper, the pipeline connecting Ca NguVang Oilfield's Wellhead Platform (WHP) to the Central Processing Platform of Bach Ho Oilfield (CPP-3) in Vietnam will be studied. Hence, this work covers several aspects, namely the theoretical study, the modeling using Excel as well as using specialized software OLGA, and finally the application for a real case in the petroleum industry in Vietnam.
\end{abstract}

\section{Keywords}

Flow Assurance, Pipeline Design, Thermal Insulation, Wax Deposition, Heat Transfer in Pipeline

\section{Introduction}

Oil and gas fields in Vietnam are located hundreds of kilometers offshore in 
which producing and processing procedures are separated and conducted on different platforms. These platforms are connected by a pipeline system lying on the seabed. Specifically, crude oil is transferred from the Wellhead Platform of Ca NguVang field to the Central Processing Platform of Bach Ho field, where crude oil is under processing, by the approximately-25-kilometer-length pipeline (Figure 1).

Ca NguVang field is operated by Hoan Vu Joint Operating Company. As a result of an average reserve, which ranges between $6200-20,000$ barrels/day [1], it is impossible to develop this field independently because of economic issues. In order to minimize the development cost, it is suggested that Ca NguVang field should be connected with Bach Ho field by the subsea pipeline system. The produced oil from $\mathrm{Ca}$ NguVang field has a high concentration of paraffin, which tends to cause wax deposition in pipes.

Crude oil is a mixture of waxes, aromatics, naphthenes, asphaltenes, and resins. At typical reservoir temperatures and pressure, wax molecules are dissolved in the crude oil. As the produced oil flows through a subsea pipeline lying on the ocean floor, its temperature drops below WAT (Wax Appearance Temperature) because of heat loss along the pipeline [2]. Waxes in the oil form deposits on the inner pipe wall then become thicker with time, which leads to serious problems related to flow assurance [3]. In the worst-case scenario, the whole process of transport must be stopped for the replacement of the plugged section of the pipe. The estimated cost could be up to approximately $\$ 30,000,000$ per incident [4].

In fact, there were a number of accidents related to flow assurance which was attributed to wax deposition. From 1992 to 2002, over 50 cases of pipeline blocking due to wax deposition were reported in Gulf of Mexico [5]. In which, the replacing cost was $\$ 5,000,000$, with a downtime of 40 days constituted approximately $\$ 25,000,000$ [6]. One of the most severe cases happened at Staffa field in North Sea, UK [7]. The offshore platform was terribly damaged by wax deposition; to the point that it was left abandoned at the total cost of $\$ 100,000,000[6]$.

In respond to the consequences of wax deposition, many studies of flow assurance are now focusing on remedy and prevention techniques. One of the solutions was to prevent the heat loss along the pipe, in which choosing thermal isolating materials and design optimum thickness for the coat was mentioned in

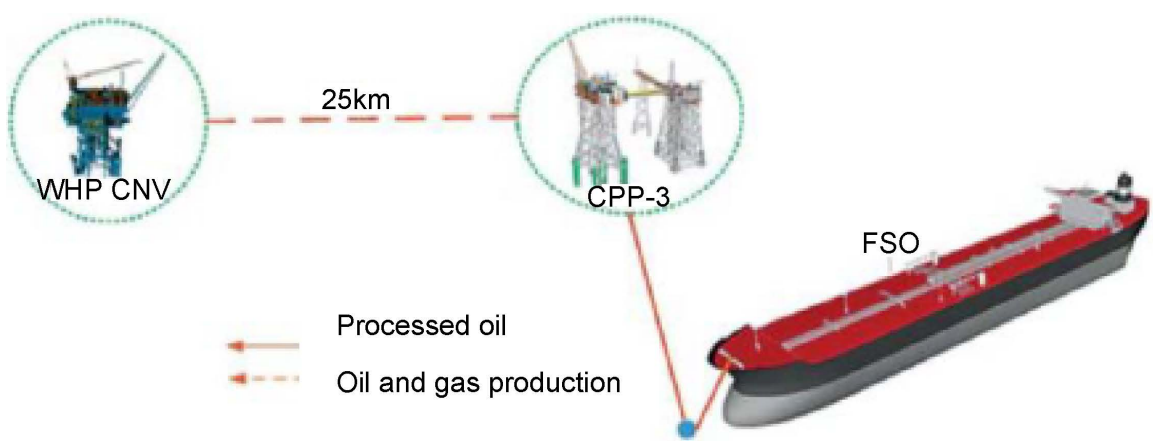

Figure 1. Schematic of crude oil transport system [1]. 
this article. Additionally, the amount of wax deposition also depends on the flow operational parameters such as flowrate, temperature, pressure. Therefore, examining the wax thickness and the wax deposition position by evaluating these parameters is critical to optimize the transportation of produced oil.

\section{Literature Review}

\subsection{Fundamentals of Wax}

Crude oil is a liquid organic substance. It is made up of hydrocarbons, which are composed of hydrogen and carbon atoms, and some proportions of impurities such as $\mathrm{CO}_{2}, \mathrm{H}_{2} \mathrm{~S}$, etc. Components of hydrocarbon vary widely, ranging from the simplest one-methane $\left(\mathrm{CH}_{4}\right)$, to the complex chemical substances in which the number of carbon atoms can reach over 60 [8]. Therefore, crude oil contains a considerable amount of wax, whose composition consists of low molecular weight alkanes $\left(\mathrm{C}_{18}-\mathrm{C}_{36}\right)$ and high molecular weight cycloalkanes $\left(\mathrm{C}_{36}-\mathrm{C}_{60}\right)$. Overall, wax is similar to the natural beeswax [9].

The critical factor leading to the phenomenon of wax formation is the fact that fluid temperature flowing through the pipeline is lower than wax appearance temperature (WAT) [2].

\subsection{Heat Loss during Crude Oil Transport}

The reason of heat loss during crude oil transport is due to heat transfer from the fluid to the environment surrounding pipeline. Particularly, heat transfer process is supposed to be divided into three patterns [10]: 1) convection-the transfer of heat from the fluid inside to the inner wall of the pipe, and from the outer wall of the pipe to the outside environment, 2) conduction-the transfer of heat from the inner wall of the pipe to the outer one and 3) radiation. However, the effect of radiation is minor, so it can be neglected [10]. Additionally, for pipeline design and material selection, it is essential that heat transfer due to conduction be minimized.

Heat transfer is primarily influenced by the following factors [11]: 1) the fact that the pipeline is buried underground, placed on the surface, or lay on the seabed, 2) the ambient environment, 3) the depth of pipeline buried, 4) thermal characteristics of coating materials and 5) the thickness of pipeline. In this certain situation, the pipeline connecting WHP-CNV to CPP-2 is laid on the seabed, so the effect of factors (1), (2), (3) is constant. As a result, factor (4) in conjunction with factor (5) is suggested to be focused. Thus, pipeline design and material selection depend on total heat transfer coefficient of the pipeline.

Formulas for computing total heat transfer coefficient [11]: consider the following schematic of multi-layer pipe (Figure 2):

The amount of heat transfer through unit length of pipeline is given by

$$
H=\frac{2 \pi}{\sum_{1}^{n} \frac{\ln \left(\frac{r_{j o}}{r_{j i}}\right)}{k_{j}}}
$$


In which $k$ is thermal conductivity of a certain layer of the pipe $(\mathrm{W} / \mathrm{m} \cdot \mathrm{K}) . r_{j o}$, $r_{j i}$ are respectively inner and outer radius of a certain layer of the pipe $(\mathrm{m})$.

Heat transfer coefficient due to conduction heat $h\left(\mathrm{~W} / \mathrm{m}^{2} \cdot \mathrm{K}\right)$ of a particular coating is given by

$$
h=\frac{H}{2 \pi r_{1 i}}
$$

Total heat transfer coefficient $U\left(\mathrm{~W} / \mathrm{m}^{2} \cdot \mathrm{K}\right)$ is related to three patterns of heat transfer according to the following relation

$$
\frac{1}{U}=\frac{1}{h_{\text {convection }}}+\frac{1}{h_{\text {conduction }}}+\frac{1}{h_{\text {radiation }}}
$$

From a material selection aspect of pipeline design, it is acceptable to neglect the effect of convection and radiation of heat, leading to the simple form of total heat transfer coefficient equation presented below

$$
U=h_{\text {conduction }}
$$

\subsection{Design Thickness of Thermal Insulating Materials}

\subsubsection{Layered Structure of Pipeline}

Pipelines are usually manufactured from coating layers with their specific functions (Figure 3) [12]: 1) Steel: flow conductor having high pressure capacity, 2)

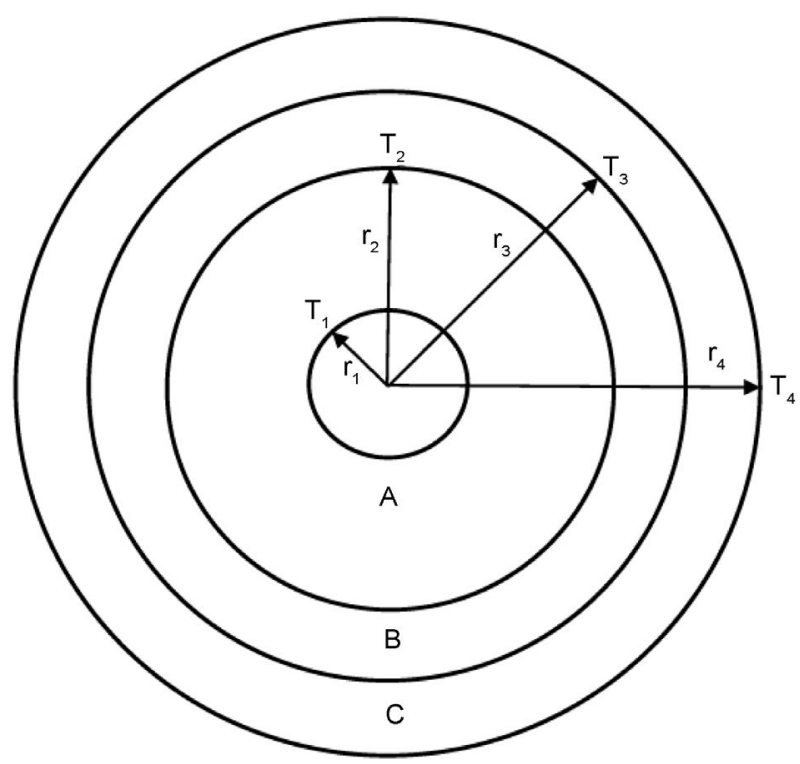

Figure 2. Schematic of a multi-layer pipe. $T_{n}$-layer $n, r_{n}$ radius of layer $n$.

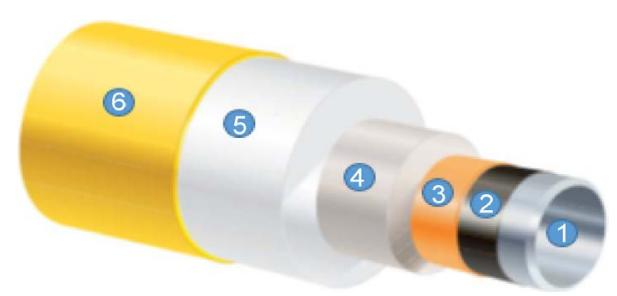

Figure 3. Pipelines manufactured from coating layers. 
Fusion Bond Epoxy (FBE): layer protecting pipelines from corrosion, 3) Polypropylene Adhesive (PP Adhesive): gel layer connecting two adjacent layers, 4) Polypropylene Solid (PP Solid): layer supporting PU Foam layer, 5) Polyurethane Foam (PU Foam): thermal insulating layer and 6) Concrete Weight Coating (CWC): layer made up of concrete helping maintain stability and protect the whole pipeline. In addition, CWC may also perform a secondary function as the thermal insulation.

\subsubsection{Fundamentals of Heat Analysis}

Changes in the heat along a pipeline are related to the variation of the level of thermal insulation of coatings, which means total heat transfer coefficient $U$ needs analyzing [11]. The value of $U$ reflects the degree of heat loss associated with the amount of wax deposition. Therefore, it is necessary to control the value of $U$ so that the temperature along the pipeline remains higher than the one at which wax appearance occurs as long as possible.

\section{Input Data}

Information and data about dimension of pipeline (Table 1) and characteristics of materials (Table 2) are shown below.

According to Table 2, PU Foam, which performs the major function of heat insulation, possesses the lowest value of heat conductivity. Additionally, properties of produced fluid, production data and data relating to environment are presented in the following Tables 3-5.

Table 1. Suggested data of steel pipe for CNV field.

\begin{tabular}{cccccc}
\hline \multirow{2}{*}{ Length $(\mathrm{m})$} & \multicolumn{2}{c}{ Diameter $(\mathrm{mm})$} & & Thickness $(\mathrm{mm})$ & Roughness $(\mathrm{mm})$ \\
\cline { 2 - 3 } & OD & ID & & & \\
\hline 24.921 & 273.10 & 232.9 & 20.1 & 0.0457 \\
\hline
\end{tabular}

Table 2. Characteristics of pipeline material.

\begin{tabular}{cccc}
\hline Material & Heat conductivity $(\mathrm{W} / \mathrm{m} \cdot \mathrm{K})$ & Density $\left(\mathrm{kg} / \mathrm{m}^{3}\right)$ & Heat capacity $(\mathrm{J} / \mathrm{kg} \cdot \mathrm{K})$ \\
\hline Steel (API5LX65) & 45.0 & 7850 & 460 \\
FBE & 0.3 & 1450 & 1350 \\
PP Adhesive & 0.22 & 900 & 1000 \\
PU Foam & 0.04 & 165 & 1600 \\
PP Solid & 0.215 & 900 & 1800 \\
CWC & 2.0 & 2242.60 & 1000 \\
\hline
\end{tabular}

(Extracted from MsiKenny Company).

Table 3. Properties of produced fluid.

\begin{tabular}{cc}
\hline Density $(\mathrm{g} / \mathrm{ml})$ & 0.8136 \\
Cloud point temperature $\left({ }^{\circ} \mathrm{C}\right)$ & 30 \\
Wax content $(\%)$ & 16.8 \\
$\operatorname{WAT}\left({ }^{\circ} \mathrm{C}\right)$ & 59.8 \\
\hline
\end{tabular}


It is precise that produced oil from Ca NguVangField is categorized as the light crude oil with high wax content. Besides, both cloud point temperature and WAT outnumber ambient temperature of the environment $\left(30^{\circ} \mathrm{C}\right.$ and $59.8^{\circ} \mathrm{C}$ respectively in comparison with $25.13^{\circ} \mathrm{C}$ ), which contributes to wax appearance and hinder restart operation after shut-in pipeline. Furthermore, Ca NguVang field is in the beginning stage of production with a relatively low value of water cut, which is the proportion of water produced to the total liquid (2 percent).

\section{Results and Implications}

\subsection{Thickness of Coating Layers}

On the purpose of transporting crude oil through subsea pipeline safely from $\mathrm{Ca}$ NguVang field to CPP-3 of Bach Ho field, the thickness of each coating is computed in order to corresponds with previously determined $U=1.91 \mathrm{~W} / \mathrm{m}^{2} \cdot \mathrm{K}[1]$. Calculation steps as following: 1) consider each thickness (column 4 of Table 6) as a variable, 2) calculate outer and inner radii of the other layers (column 2 and 3 of Table 6), 3) compute values for column 5,4) calculate $H$, the amount of heat transfer through unit length using formula $(\mathrm{I}), 5)$ compute total heat transfer

Table 4. Production data.

$\begin{array}{cc}\text { Oil production (barrel/day) } & 6100 \\ \text { Gas Oil ratio }\left(\mathrm{ft}^{3} / \text { barrel) }\right. & 2390 \\ \text { Water cut }(\%) & 2\end{array}$

Table 5. Data relating to environment.

\begin{tabular}{cc}
\hline Density $\left(\mathrm{kg} / \mathrm{m}^{3}\right)$ & 1025 \\
Seabed temperature $\left({ }^{\circ} \mathrm{C}\right)$ & 25.13 \\
Surface temperature $\left({ }^{\circ} \mathrm{C}\right)$ & 27.57 \\
Air temperature $\left({ }^{\circ} \mathrm{C}\right)$ & 27 \\
Steam velocity $(\mathrm{m} / \mathrm{s})$ & 0.63 \\
Wind velocity $(\mathrm{m} / \mathrm{s})$ & 12.1 \\
\hline
\end{tabular}

Table 6. Thickness of different layers in the pipeline.

\begin{tabular}{cccccc}
\hline Material & $\begin{array}{c}\text { Inner radius } r_{i} \\
(\mathrm{~mm})\end{array}$ & $\begin{array}{c}\text { Outer radius } r_{o} \\
(\mathrm{~mm})\end{array}$ & $\begin{array}{c}\text { Thickness } \\
(\mathrm{mm})\end{array}$ & $\begin{array}{c}\ln \left(\frac{r_{o}}{r_{i}}\right) \\
2 \pi k\end{array}$ & $\begin{array}{c}\text { Results of thickness } \\
(\mathrm{mm})\end{array}$ \\
\hline Steel & 116.45 & 136.55 & 20.1 & 0.00056 & 20.1 \\
FBE & 136.55 & 136.55 & 0 & 0 & 0.15 \\
PP Adhesive & 136.55 & 136.55 & 0 & 0 & 0.35 \\
PP Solid & 136.55 & 136.55 & 0 & 0 & 3.5 \\
PU Foam & 136.55 & 136.55 & 0 & 0 & 25.21 \\
PP Solid & 136.55 & 136.55 & 0 & 0 & 4 \\
CWC & 136.55 & 136.55 & 0 & 0 & 48.22 \\
H & 1775.70 & $\mathrm{~W} / \mathrm{m} \cdot \mathrm{K}$ & & & \\
U & 2426.90 & $\mathrm{~W} / \mathrm{m}^{2} \cdot \mathrm{K}$ & & & \\
\hline
\end{tabular}


coefficient $U$ using formula (II) and (IV), 6) use tool Solver in Excel for every thickness with pre-determined $U\left(U=1.91 \mathrm{~W} / \mathrm{m}^{2} \cdot \mathrm{K}\right)$. Results are shown in the last column in Table 6 which is similar with those derived from OLGA.

From Table 6, PU Foam and CWC coatings possess the largest thickness with the value of $25.21 \mathrm{~mm}$ and $48.22 \mathrm{~mm}$ respectively because these two coatings are responsible for pipeline thermal isolating. The question here is that whether changing or even eliminating the thickness of some layer could cut off some cost without causing heat loss in the pipeline. The following part is intended to discuss this aspect.

\subsection{Wax Deposition Level Surveillance Attributed to the Change in Coating Thickness}

To evaluate quantitatively influences of the existence of the coating layers, especially CWC and PU Foam, the following five cases are considered in Table 7, in which the second case referred to the result of Table 6.

The wax deposition level after 30 days can be observed in Figure 4. Obviously, in cases 1, 3 and 5, wax appears near the start point of the pipeline; also in these cases, maximum wax thickness is relatively large. Meanwhile, case 2 and 4, the differences cannot be distinguished.

The thickness computed in Table 6 with heat transfer coefficient $U=1.91$ $\mathrm{W} / \mathrm{m}^{2} \cdot \mathrm{K}$ is $0.151 \mathrm{~mm}$. The result corresponds to case 2 in Table 7 .

Table 7. Wax deposition level after 30 days with different coating thickness.

\begin{tabular}{|c|c|c|c|c|c|c|c|c|}
\hline \multirow{2}{*}{ Case } & \multicolumn{6}{|c|}{ Thickness (mm) } & \multirow{2}{*}{$\begin{array}{l}\text { Total heat transfer } \\
\text { coefficient }\left(\mathrm{W} / \mathrm{m}^{2} \cdot \mathrm{K}\right)\end{array}$} & \multirow{2}{*}{$\begin{array}{l}\text { Wax thickness } \\
(\mathrm{mm})\end{array}$} \\
\hline & SteelFBE $\mathrm{F}$ & P Adhesive & PP Solid & PU Foam & PP Solid & CWC & & \\
\hline 1 & $20.1-$ & - & - & - & - & - & 669.12 & 1.80 \\
\hline 2 & 20.10 .15 & 0.35 & 3.5 & 25.21 & 4.00 & 48.22 & 1.91 & 0.151 \\
\hline 3 & 20.10 .15 & 0.35 & 3.5 & - & 4.00 & 48.22 & 20.58 & 1.19 \\
\hline 4 & 20.10 .15 & 0.35 & 3.5 & 25.21 & 4.00 & - & 1.96 & 0.153 \\
\hline 5 & 20.10 .15 & 0.35 & 3.5 & - & 4.00 & - & 31.30 & 1.37 \\
\hline
\end{tabular}

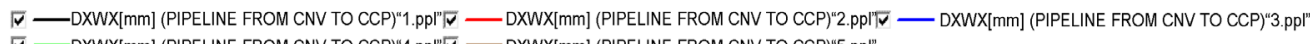

OLGA* $\nabla$-DXWX[mm] (PIPELINE FROM CNV TO CCP)"4.ppl"『 —DXWX[mm] (PIPELINE FROM CNV TO CCP)"5.ppl"

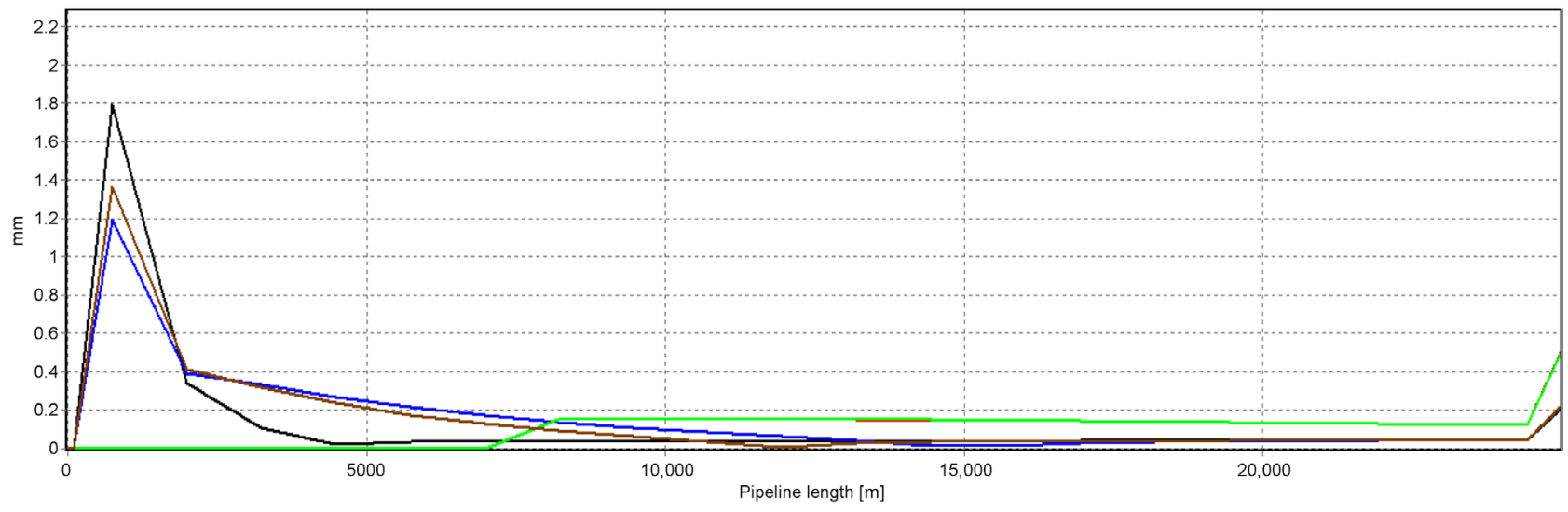

Figure 4. Thickness wax deposition after 30 days with different coating thickness. (DXWX: Wax thickness). 
Case 1 is the case in which pipeline is simply made of steel $(20.1 \mathrm{~mm})$, with no other coating. In this circumstance, total heat transfer coefficient $U$ rises abruptly $\left(669.12 \mathrm{~W} / \mathrm{m}^{2} \cdot \mathrm{K}\right)$; consequently, heat loss in pipeline is so serious that wax molecules crystalize earlier and form a far thicker layer $(1.80 \mathrm{~mm})$ in the inner pipe wall than that in case 2 .

Nonetheless, case 1 exists only in theory analysis due to the fact that constructing the pipeline without any protection is impossible. Besides, evaluating the effects of two thermal isolating coatings (PU Foam and CWC) requires to only change the thickness of these coatings, the rest layers are remained unchanged.

Maximum wax thickness after 30 days results in case 3, 4, 5 (changing PU Foam and CWC thickness) are presented in Table 7.

Among case 3 and 5, the fact that PU Foam (primary thermal isolating material) is omitted seriously affects the amount of wax deposition. Wax thickness has risen dramatically ( $1.19 \mathrm{~mm}$ and $1.37 \mathrm{~mm}$ respectively). In addition to case 5 , CWC is also excluded; thus, wax thickness is higher than case 3 . However, due to high heat conductivity of CWC layer $(2 \mathrm{~W} / \mathrm{m} \cdot \mathrm{K}$, just lower than that of steel), eliminating this layer do not affect wax thickness significantly.

Taking concern on circumstance 4 which only gets rid of CWC layer; because CWC heat conductivity is relatively high, wax thickness in this case increases slightly $(0.153 \mathrm{~mm}$ compare with $0.151 \mathrm{~mm}$ in case 2$)$ and can be negligible. However, it is undesirable to exclude CWC layer just for economic reason. The most important function of CWC layer is to aggravate and protect the pipeline from any mechanical impact; in other words, CWC layer strengthens and helps the pipeline win over buoyant force. Moreover, optimum thickness of CWC layer has always been considered so that it is as economical as possible.

In order to determine the optimum thickness of CWC layer, the problem relating to the force balance is considered. The whole pipeline rests on the seabed; the buoyant force, according to Archimedes, is equal to the product of the seawater density and the volume occupied by the pipeline. The weight of the pipe is the sum of the crude oil weight currently in the pipe, the steel weight and all the weights of coating. It is necessary to meet the following condition to stabilize the pipeline on the seabed: gravity force of the pipeline system is greater than Archimedes buoyant force in the case of the pipeline without crude oil. Computing Archimedes force is followed as: 1) consider CWC layer thickness as variable, 2) compute total weight of the pipeline system, 3) compute the volume of the pipeline occupying the water and water density, 4) solve the force balance equation and compare with outsourcing criteria of company. Results are presented in $\mathrm{Ta}-$ ble 8 .

From Table 8, it is obvious that weight of pipe is larger than weight of sea water per unit length and for that reason, CWC minimum thickness of $40 \mathrm{~mm}$ is chosen. New cross section area of CWC layer is reduced to $0.0477 \mathrm{~m}^{2}$ (compared to $0.0587 \mathrm{~m}^{2}$ when using $48.22 \mathrm{~mm}$ CWC layer). Consequently, the saving amount of weight could be compute as follow: 


$$
25000(\mathrm{~m})(0.0587-0.0477)\left(\mathrm{m}^{2}\right)(2242.6)\left(\frac{\mathrm{kg}}{\mathrm{m}^{3}}\right)=619123(\mathrm{~kg})=619.123(\mathrm{ton}) .
$$

Knowing the CWC outsourcing cost per ton, it is possible to calculate the total saving cost. In conclusion, as can be seen from the above calculation and analysis, PU Foam layer has the biggest effect on thermal controlling procedure; which is the reason why hindering wax deposition problem requires focusing on this layer.

After material choosing and thickness calculating, the upcoming section is to examine operational parameters (flowrate, temperature and pressure).

\subsection{Operational Parameter Analysis}

To evaluate impacts of variations of flowrate, temperature and pressure, OLGA software is utilized. In particular, the amounts of wax deposition after a 30-day period is plotted and compared to the others in each case of flowrate, temperature and pressure using the function named Parametric Study and the wax modeling of Matzain.

\subsubsection{Flowrate}

The variations of wax deposition thickness correspond to the changes in the flowrate of fluid. It is obvious from Table 9 and Figure 5 that the lower flowrate results in the thinner wax deposition as well as earlier wax appearance. This can be explained by the fact that the shear stress governed by the velocity (flowrate) of fluid tends to reduce the thickness of wax deposition. The higher value of fluid velocity (flowrate) leads to the increasing shear stress. Additionally, the flowrate also has an impact on both the heat loss along the pipeline and the capability of transferring wax crystals. The amount of heat loss is increasing with the

Table 8. Steady calculation with negligible CWC layer.

\begin{tabular}{ccc}
\hline Parameter & Unit & Value \\
\hline Weight of pipe per unit length & $\mathrm{kg} / \mathrm{m}$ & 136.41 \\
Weight of sea water per unit length & $\mathrm{kg} / \mathrm{m}$ & 92.79 \\
Minimum thickness of CWC layer & $\mathrm{mm}$ & $40^{*}$ \\
Maximum thickness of CWC layer & $\mathrm{mm}$ & $150^{*}$ \\
\hline
\end{tabular}

${ }^{*}$ : Data obtained from PV Coating, the Joint Company of PVGas)

Table 9. Results of wax deposition after 30 days with various cases of different flowrates.

\begin{tabular}{cccc}
\hline Case & $\begin{array}{c}\mathrm{Q} \\
(\mathrm{stb} / \mathrm{d})\end{array}$ & $\begin{array}{r}\text { Maximum wax deposition thickness } \\
(\text { MWDT })(\mathrm{mm})\end{array}$ & $\begin{array}{c}\text { Position at which wax starts to deposit } \\
(\text { PWD })(\mathrm{m})\end{array}$ \\
\hline 1 & 2000 & 0.192 & 741.5 \\
2 & 3000 & 0.171 & 1988 \\
3 & 4000 & 0.160 & 3234 \\
4 & 5000 & 0.156 & 5726 \\
5 & 6000 & 0.152 & 6972 \\
6 & 7000 & 0.148 & 8218 \\
\hline
\end{tabular}


time for fluid to flow along the pipeline, which is inversely proportional to the flowrate. Therefore, the position at which fluid temperature is smaller than WAT tends to be closer to the input of pipeline if the larger value of flowrate is considered. Finally, it is clear that the pipeline with higher flow rate has more capability to transport fluid in comparison with the one with lower flow rate, resulting in smaller chance of wax deposition.

\subsubsection{Temperature}

The input temperature of the pipeline, donated as $\mathrm{T}_{\mathrm{WHP}}$, affects the distribution of temperature along the pipeline, resulting in the dependence of position where wax appearance occurs onto input temperature. The appropriate value of $\mathrm{T}_{\mathrm{WHP}}$ can be obtained using equipment called Heat Exchanger. The results of how $\mathrm{T}_{\mathrm{WHP}}$ has an impact on wax deposition are given in Table 10 and Figure 6 in the case of $6000 \mathrm{stb} / \mathrm{d}$ of flowrate.

In the first case, wax deposits at the very beginning of the pipeline with the noticeable thickness of wax $(2.674 \mathrm{~mm})$, compared to the other cases $(0.151$ $\mathrm{mm})$. This is attributed to the fact that the value of WAT outnumbers the input temperature $\left(59.8^{\circ} \mathrm{C}\right.$ and $50^{\circ} \mathrm{C}$ respectively). The fundamental difference amongst the other cases is the position where wax starts to deposit. The lower $\mathrm{T}_{\mathrm{WHP}}$ is the closer to WHP wax would deposit. The similarity amongst these four cases is the equivalent wax deposition thickness when reaching stable condition (approximately $0.151 \mathrm{~mm}$ ). The reason of this occurrence is due to the similar pipeline structure and flowrate considered; therefore, all four cases experience no difference in the wax deposition after fluid flow achieves stability.

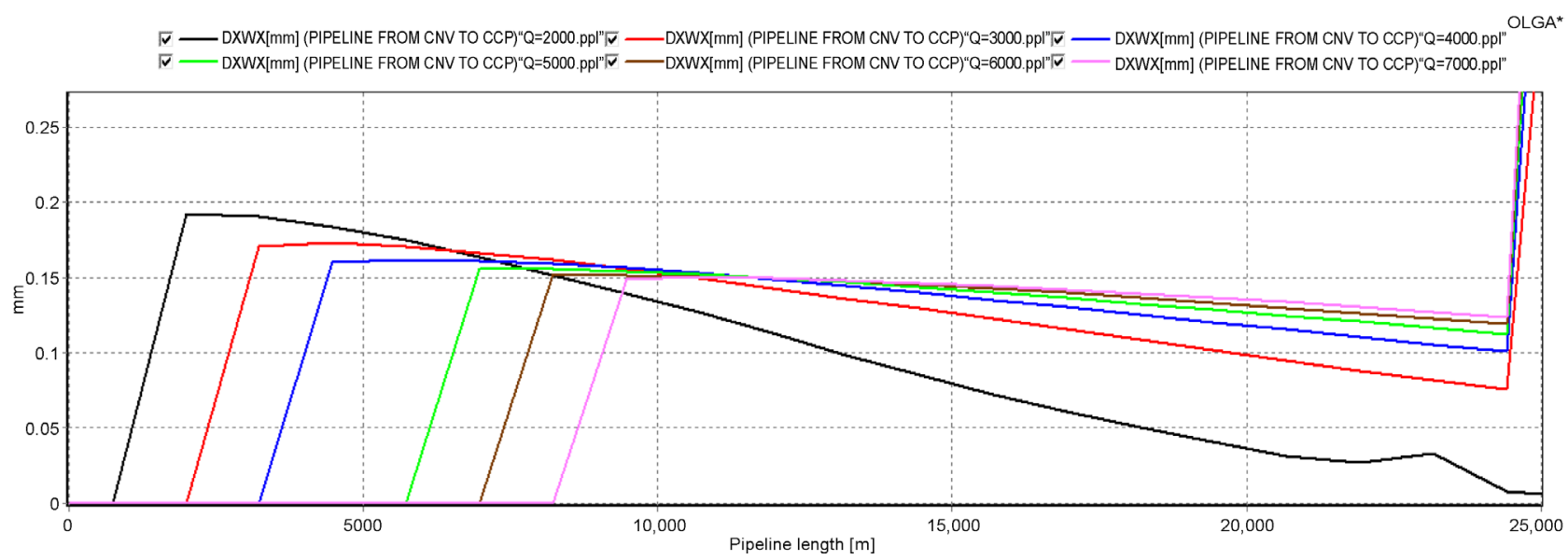

Figure 5. Results of wax deposition after 30 days with various cases of different flowrates.

Table 10. Results of wax deposition after 30 days with various cases of different inlet temperature.

\begin{tabular}{cccc}
\hline Case & $\mathrm{T}_{\mathrm{WHP}}\left({ }^{\circ} \mathrm{C}\right)$ & MWDT $(\mathrm{mm})$ & PWD $(\mathrm{m})$ \\
\hline 1 & 50 & 2.674 & 0 \\
2 & 60 & 0.151 & 741.5 \\
3 & 70 & 0.151 & 6972 \\
4 & 80 & 0.151 & 11,956 \\
\hline
\end{tabular}




\subsubsection{Pressure}

Pressure is an easily changed parameter at WHP by controlling flowrate or at $\mathrm{CPP}$ by selecting operating pressure of processing equipment. Furthermore, with a specific flowrate, these two values of pressure have effects on each other. For the sake of simplicity, the pressure at $\mathrm{CPP}$, donated as $\mathrm{P}_{\mathrm{CP}}$, will be evaluated in the case of $\mathrm{Q}=6100 \mathrm{stb} /$ day and $\mathrm{T}_{\mathrm{WHP}}=70^{\circ} \mathrm{C}$. The simulated results are shown in Table 11 and Figure 7.

From Table 11 and visual result on Figure 7, it is clearly that the distance from WHP at which wax starts to deposit is getting larger with bigger $\mathrm{P}_{\mathrm{CPP}}$. It can be explained that the lower $\mathrm{P}_{\mathrm{CPP}}$ is, the higher the WAT is. However, the magnitude

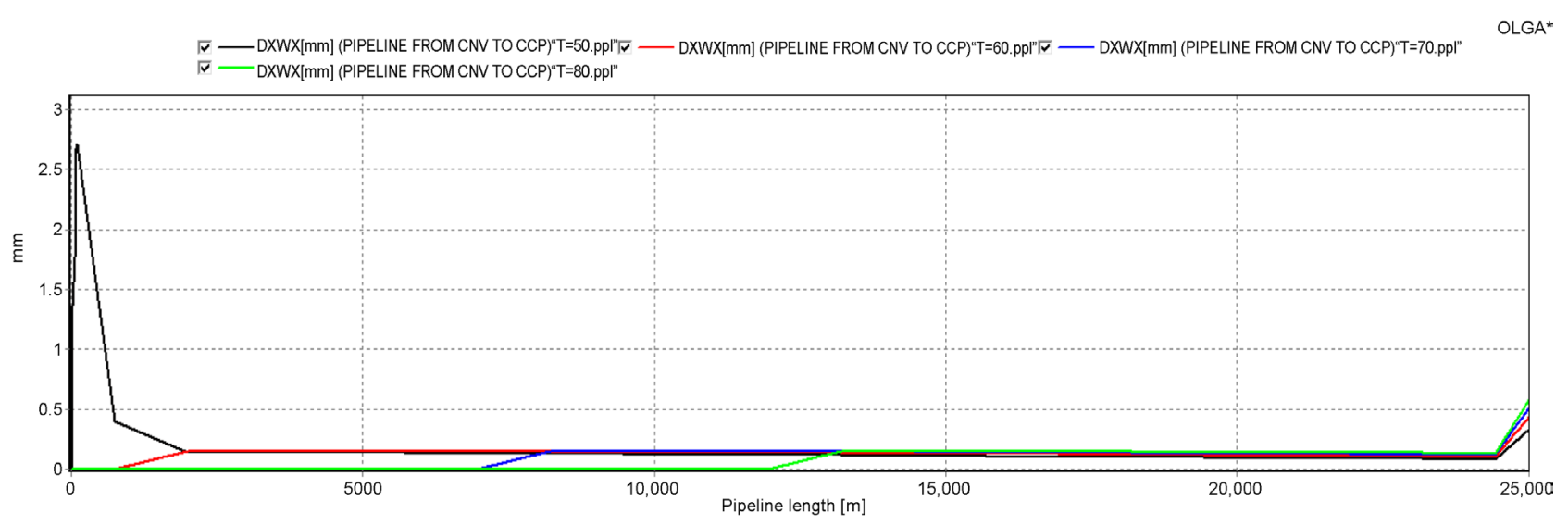

Figure 6. Results of wax deposition after 30 days with various cases of different inlet temperature.

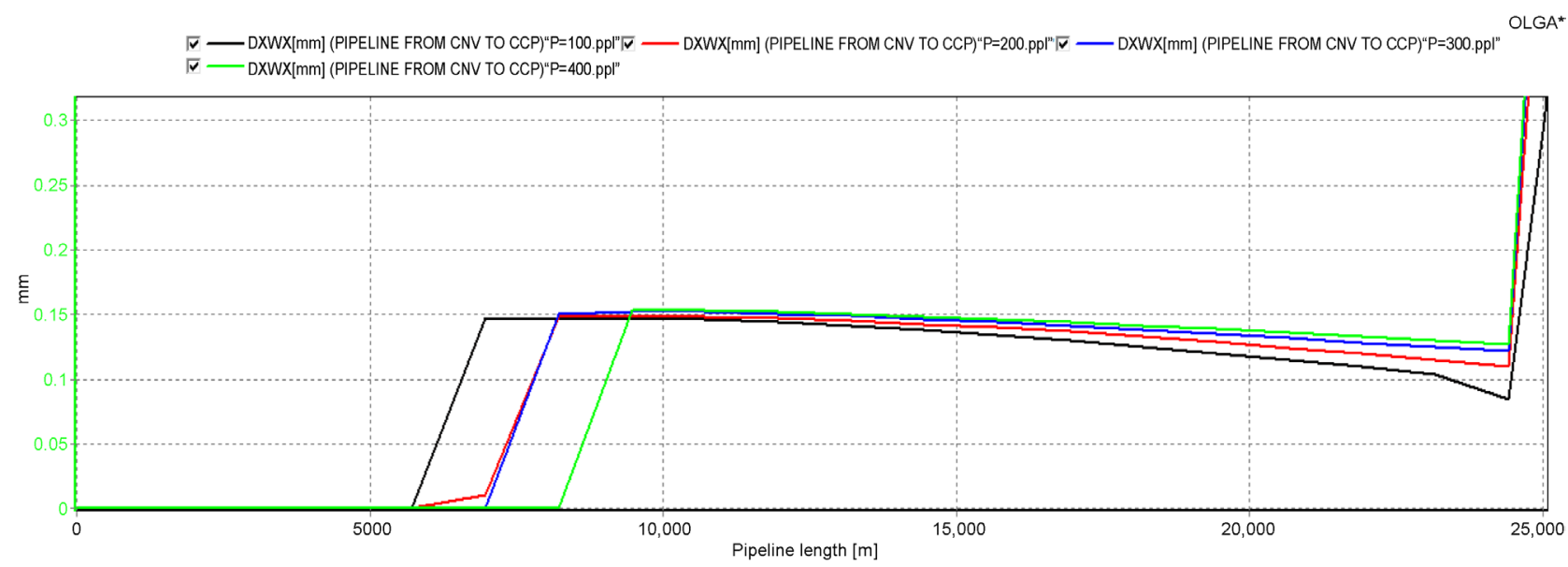

Figure 7. Results of wax deposition after 30 days with various cases of different outlet pressure.

Table 11. Results of wax deposition after 30 days with various cases of different outlet pressure.

\begin{tabular}{cccc}
\hline Case & $\mathrm{P}_{\mathrm{CPP}}(\mathrm{psia})$ & MWDT $(\mathrm{mm})$ & PWD $(\mathrm{m})$ \\
\hline 1 & 100 & 0.148 & 4480 \\
2 & 200 & 0.150 & 5726 \\
3 & 300 & 0.153 & 5726 \\
4 & 400 & 0.153 & 6972 \\
\hline
\end{tabular}


of heat loss tends to increase when $\mathrm{P}_{\mathrm{CPP}}$ is low. In four circumstances, the values of wax thickness are nearly the same (about $0.150 \mathrm{~mm}$ ). The reason to this is similar to the case of $\mathrm{T}_{\mathrm{WHP}}$.

With the result of analysis operational parameters such as flow rate, temperature and pressure, it can be concluded that: reducing wax thickness and maintaining wax in liquid form as long as possible require increasing the flow rate, temperature at the inlet of the pipe $\left(\mathrm{T}_{\mathrm{WHP}}\right)$ as well as the pressure at the outlet of the pipe. In general, three mentioned parameters have similar tendency in affecting wax depositional process.

\section{Conclusions}

In this research, two aspects are carried out for study. Firstly, as engineers of Cuu Long-Hoan Vu JOC are in charge of designing pipeline system in term of geometry and material, therefore, the primary goal of this paper is choosing thermal isolating materials and determining optimum thickness of coating layers, especially CWC and PU Foam. Thus, issues relating to geometry of pipeline system will not be concerned. In pipeline design and material selection issue, $\mathrm{PU}$ Foam and CWC coatings have the largest thickness values. Amongst these coatings, PU Foam is the one performing thermal isolating function; thus, in order to minimize wax deposition as well as its thickness, the thickness of this coating must be carefully computed. In addition, CWC coating's primary role is to stabilize and protect the whole pipeline in the marine environment so it is designable to adjust the thickness of these coatings so that issues relating to economy are improved.

Secondly, apart from the aspect of material, operational parameters namely flowrate, temperature and pressure will be considered to know how variation of these parameters may affect wax deposition. These operating parameters are vital in flow assurance facet. To illustrate how to apply this paper to a certain circumstance, authors consider the pipeline connecting WHP-CNV and CPP-3 Bach Ho Oilfield. All the information about production, ambient environment, characteristics of coating materials and properties of fluid transported through this route is necessary in progress of evaluating the degree of wax formation and deposition. For example, production data consists of the value of flowrate which in turn influences the position where wax starts to deposit as well as thickness of wax deposition. In addition, the ambient temperature also has the similar influences on this problem despite coating materials are thermal isolating. Moreover, the paraffin content of produced fluid has a profound impact on the level and the period of wax deposition. These data were provided by Cuu Long-Hoan $\mathrm{Vu}$ JOC, hence we can consider the results reasonable. It is recalled that the crude oil is produced at WHP (Well Head Platform) and flows through the pipeline resting on the ocean floor then reaches the end point at CPP (Central Processing Platform). Therefore, to avoid wax deposition occurring near the inlet of the pipeline, which leads to undesired pressure loss, and minimize maximum wax thickness, it is recommended that flowrate, temperature at WHP or pressure at 
CPP should be decreased. However, changes in these parameters must correspond to technical and economic availability.

Supporting the calculation in this subject, Excel and OLGA are utilized. However, because of specialized function, OLGA software is used to examine effects of operational parameters in addition to determining optimum thickness of coating layers which can be achieved simply using Excel. Overall, the results derived from Excel are similar with those obtained from OLGA software.

The method mentioned above just partially tackles wax deposition problem and do not completely eliminate it. Therefore, this is the limitation of the approach. Eventually, if wax thickness increases to a particular value, PIG (pipeline inspection gauge) must be sent into the pipeline to scrape off the wax to maintain the flow.

\section{References}

[1] Phung Dinh Thuc (2016) Connection between Ca Ngu Vang Oilfield and Bach Ho Oilfield. Vietnam Petroleum Journal.

[2] Rosvold, K. (2008) Wax Deposition Models. Master Thesis, Norwegian University.

[3] Reistle, C.E. (1932) Paraffin and Gongealing-Oil Problems. Department of Commerce, Bureau of Mines and University of Wyoming.

[4] Lee, H.S. and Fogler, H.S. (2001) Combined Convective Heat and Mass Transfer Analysis of Wax Deposition under Turbulent Flow Conditions. Department of Chemical Engineering, University of Michigan and Chevron Energy Technology Company, Housten.

[5] Zhu, T., Walker, J.A. and Liang, J. (2008) Evaluation of Wax Deposition and Its Control during Production of Alaska North Slope Oils-Final Report. United States Department of Energy and National Energy Technology Laboratory.

[6] Singh, P. (2000) Gel Deposition on Cold Surfaces. PhD Thesis, University of Michigan.

[7] Gluyas, J.G. and Underhill, J.R. (2003) The Staffa Field, Block 3/8b, UK North Sea. Memoirs, 20, 327-333. https://doi.org/10.1144/GSL.MEM.2003.020.01.28

[8] Qabazard, H.M. (2013) An Introduction to the Oil Industry \& OPEC. OPEC Secretariat Public Relations \& Information Department, Austria.

[9] Rønningsen, H.P., Bjørndal, B., Hansen, A.B. and Pedersen, W.B (1991) Wax Precipitation from North Sea Crude Oils Crystallization and Dissolution Temperatures, and Newtonian and Non-Newtonian Flow Properties. Energy \& Fuels, 5, 895-908. https://doi.org/10.1021/ef00030a019

[10] Huang, Z. (2011) Application of the Fundamentals of Heat and Mass Transfer to the Investigation of Wax Deposition in Subsea Pipelines. PhD Thesis, University of Michigan.

[11] BauckIrmann-Jacobsen, T. (2015) Flow Assurance-A System Perspective. University of Oslo.

[12] William Guan, S. (2005) Advance Onshore and Offshore Pipeline Coating Technologies. China International Oil \& Gas Pipeline Technology (Integrity) Conference \& Expo. 
Submit or recommend next manuscript to SCIRP and we will provide best service for you:

Accepting pre-submission inquiries through Email, Facebook, LinkedIn, Twitter, etc. A wide selection of journals (inclusive of 9 subjects, more than 200 journals)

Providing 24-hour high-quality service

User-friendly online submission system

Fair and swift peer-review system

Efficient typesetting and proofreading procedure

Display of the result of downloads and visits, as well as the number of cited articles Maximum dissemination of your research work

Submit your manuscript at: http://papersubmission.scirp.org/

Or contact ojce@scirp.org 